\title{
p53 as a prognostic factor in adrenocortical tumors of adults and children
}

S.T. Sredni ${ }^{1,2}$ M.C.N. Zerbini ${ }^{3}$, M.R. Latorre ${ }^{4}$ and V.A.F. Alves ${ }^{3}$
Correspondence

S.T. Sredni

Rua Emílio de Menezes, 56/apto. 21

01231-020 São Paulo, SP

Brasil

Fax: +55-11-3667-5753

E-mail: ssredni@ludwig.org.br

Research supported by FAPESP (No. 96/2272-0), and FMUSP Foundation. ....................

Received April 23, 2002 Accepted September 30, 2002

\author{
${ }^{1}$ Departamento de Patologia, Hospital do Câncer, São Paulo, SP, Brasil \\ ${ }^{2}$ Instituto Ludwig de Pesquisa sobre o Câncer, São Paulo, SP, Brasil \\ ${ }^{3}$ Departamento de Patologia, Faculdade de Medicina, Universidade de São Paulo, \\ São Paulo, SP, Brasil \\ ${ }^{4}$ Departamento de Epidemiologia, Faculdade de Saúde Pública, \\ Universidade de São Paulo, São Paulo, SP, Brasil
}

\begin{abstract}
Mutations of the tumor suppressor gene p53 have been considered to be important determinants in several kinds of human cancer. Accumulation of $\mathrm{p} 53$ protein has been reported to correlate with more aggressive clinical behavior in some neoplasms. The role of $\mathrm{p} 53$ expression in adrenal cortical tumors (ACT) has not been elucidated but some studies have suggested its correlation with malignant behavior. Our objective was to determine if there is a correlation between the expression of immunoreactive p53 and the biological behavior of ACT. Fifty-seven ACT (21 from children and 36 from adults) were evaluated for $\mathrm{p} 53$ expression by immunohistochemistry in formalinfixed paraffin-embedded tissue and analyzed in terms of outcome. The p53 parameter was utilized semiquantitatively. Tumors were classified as p53 negative when no positivity was observed, or when only few cells showed weak positivity $(0 / 1+)$ and scored as p53 positive when there was a diffuse and strong nuclear positivity $(2+/ 3+)$. In children, $\mathrm{p} 53$ positivity was associated with clinically malignant ACT and p53 negativity was associated with clinically benign ACT $(\mathrm{P}=$ 0.026). In adults' ACT, p53 positivity had an effect on disease-free survival $(\mathrm{P}<0.001)$ and also correlated with Weiss score, with a cutoff $=4(\mathrm{P}=0.04)$. p53 expression was related to the clinical behavior of $\mathrm{ACT}$ in both children and adults and these findings seem to support a role for p53 in ACT progression.
\end{abstract}

Key words

- Adrenal cortical tumors

- Histology

- p53

- Immunohistochemistry
No group of neoplasms has proved to be more difficult to analyze than those of endocrine and neuroendocrine lineages. Subsequent metastatic spread has been noted after removal of innocuous-appearing primary endocrine tumors (1). Conversely, histologically malignant tumors frequently behave in a benign fashion. For adrenocortical tumors (ACT) the situation is even more complex.
Tang and Gray (2), reviewing 16 cases of ACT with malignant behavior and 23 ACT with a benign course, found that weight was the parameter that most consistently correlated with outcome. The age distribution of ACT is bimodal with peaks in the first and fifth decades and the biological behavior in children seems to be quite different from that observed in adults (3-7). Failure of conven- 
tional gross and light microscopy exams to predict the clinical course of ACT has stimulated several groups to look for other methods to improve the determination of the biological potential of this group of neoplasms.

Three separate sets of criteria claim to distinguish benign from malignant ACT. These systems have been proposed by Hough et al. (8), by Weiss (9) and by Van Slooten et al. (10). Hough et al. (8) developed an index of malignancy based on the presence or absence of 12 criteria, 7 of them histological and 5 non-histological. The features commonly associated with malignant tumors are as follows: i) diffuse growth pattern, ii) vascular invasion, iii) necrosis, iv) board fibrous bands, v) capsular invasion, vi) more than one mitotic figure per 10 high-power fields (HPF), vii) moderate to marked pleomorphism, viii) tumor mass greater than $100 \mathrm{~g}$, ix) urinary ketosteroid levels higher than 10 mg g creatinine ${ }^{-1} 24 \mathrm{~h}^{-1}, \mathrm{x}$ ) absence of response to ACTH, xi) virilization (with or without Cushing's syndrome) or lack of tumor function, and xii) patient weight loss greater than 10 pounds. Van Slooten et al. (10) assessed seven parameters according to their value in discriminating metastasizing from non-metastasizing neoplasms. The parameters are as follows: i) extensive regressive changes, ii) loss of normal structure, iii) moderate to marked nuclear atypia, iv) moderate to marked nuclear hyperchromasia, $v$ ) abnormal nucleoli, vi) mitotic rate greater than 2 mitotic figures per $10 \mathrm{HPF}$, and vii) vascular or capsular invasion. Weiss (9) proposed a system involving only histological parameters: i) nuclear grade III or IV according to Fuhrman's parameters for renal cell carcinomas, ii) mitotic rate higher than 5 per $50 \mathrm{HPF}$ in the most active areas of the tumor, iii) atypical mitotic figures, iv) clear cells comprising $25 \%$ or less of the tumor, v) diffuse (solid) architecture in more than $1 / 3$ of the tumor, vi) necrosis, vii) unequivocal venous invasion, viii) unequivocal sinusoidal invasion, and ix) capsular invasion. Us- ing this system he observed that tumors with four or more of these criteria presented a malignant clinical outcome. Cagle et al. (5), comparing ACT in children and adults, found that size was the only predictor of malignancy in pediatric tumors. All pediatric tumors weighing more than $500 \mathrm{~g}$ had malignant behavior and all but one weighing less than $500 \mathrm{~g}$ were benign.

The $\mathrm{p} 53$ tumor suppressor gene has been recognized as one of the most important cancer-related genes. p53 mutations are believed to be involved in tumor genesis or tumor progression and have been reported to be associated with the aggressiveness or poor prognosis of many human tumors (11-14). Immunohistochemical reactivity for p53 is not a totally reliable indicator of the presence of mutations but has been demonstrated to be associated with poor prognosis in many tumors $(11-13,15)$.

The role of $\mathrm{p} 53$ expression in ACT is still not understood, but the findings of some studies support a role for $\mathrm{p} 53$ in the progression of this tumor $(14,16-19)$. The present study was conducted on 57 ACT specimens from children and adults to determine the frequency of $\mathrm{p} 53$ protein expression and to attempt to correlate this with clinical behavior.

Formalin-fixed paraffin-embedded sections of 57 ACT specimens stained with hematoxylin-eosin were reviewed without operator knowledge of the clinical outcome. They were evaluated for the nine histopathological parameters according to the Weiss system (9) and for p53 expression by immunohistochemistry.

ACT specimens from children $(<16$ years, $\mathrm{N}=21)$ and adults $(>15$ years, $\mathrm{N}=36)$ were analyzed and the behavior of the histopathological and immunohistochemical parameters were compared in clinically benign versus clinically malignant tumors. Tumors were considered to be clinically benign when the patients were alive without evidence of recurrence or metastatic disease after a follow- 
up of at least 24 months. Tumors were considered to be clinically malignant when the patients had recurrence, documented metastases or a fatal outcome due to the tumor at any time of follow-up.

Sections stained with hematoxylin-eosin were reviewed in each case.

The following parameters were evaluated according to the Weiss system (9). a) High nuclear grade (grades III or IV). b) Mitotic count higher than 5 per 50 HPF, evaluated by counting 10 random HPF in the area with the largest numbers of mitotic figures on the five slides with the largest numbers of mitoses. If fewer than five slides were available for a case, a correspondingly larger number of fields per slide was used, for a total of $50 \mathrm{HPF}$. c) Atypical mitotic figures: mitotic figures that definitely showed an abnormal distribution of chromosomes or an excessive number of mitotic spindles. d) Eosinophilic tumor cell cytoplasm ( $\geq 75 \%$ tumor cells): $25 \%$ or less clear or vacuolated cells resembling the normal zona fasciculata. e) Diffuse architecture ( $\geq 1 / 3$ of tumor): one third of the tumor formed patternless sheets of cells (no evidence of any organization pattern, such as a nesting or trabecular pattern). f) Necrosis (when occurring at least in confluent nests of cells). g) Unequivocal venous invasion (endothelial-lined vessel with smooth muscle in the wall). h) Unequivocal sinusoidal invasion (endotheliallined vessel with no smooth muscle in the wall). i) Capsular invasion: nests or cords of tumor extending into or through the capsule, with a corresponding stromal reaction.

According to Weiss et al. (20) data, three of these nine histological findings were found only in malignant tumors: a mitotic rate greater than 5 per $50 \mathrm{HPF}$, atypical mitotic figures and venous invasion.

The p53 protein was detected using a specific monoclonal antibody (DO-7, Dako Corp., Carpinteria, CA, USA) previously optimized at 1:100 dilution using standard immunohistochemical methods on $5-\mu \mathrm{m}$ thick paraffin sections. Appropriate positive and negative controls were prepared for every staining batch. Vimentin reactions were also performed for each case to be sure that the p53 reactions were reliable, and only the cases with a vimentin-positive internal control (fibroblasts, endothelial cells, etc.) were included in the study. The parameter was evaluated semiquantitatively. Tumors were classified as p53 negative when no positivity was observed or when only few cells showed weak positivity $(0 / 1+)$ and $\mathrm{p} 53$ positive when there was a diffuse and strong nuclear positivity $(2+/ 3+)$.

All data were analyzed using the Epi-Info version 6.0 and SPSS for Windows software. p53 protein expression was compared to clinical epidemiological aspects, clinicopathological stage, histology and outcome using the chi-square test with Yates' correction. Overall survival was determined by the product limit estimator method (KaplanMeier) and the log-rank test was used to compare the survival curves.

We studied 21 children's ACT ( $<16$ years) and 36 adults' ACT ( $>15$ years). Among the children's tumors, only 3 were classified as clinically malignant and all of them were p53 positive. Among the 18 clinically benign children's tumors, only 4 were p53 positive. Among the 11 clinically malignant adults' tumors 2 were $\mathrm{p} 53$ positive and both had more than 3 Weiss parameters (Weiss $\geq 4$ ) each.

For children p53 positivity was associated with clinically malignant ACT and p53 negativity was associated with clinically benign ACT $(P=0.026)$ (Table 1). In adults' ACT, p53 positivity had an effect on disease-free survival $(\mathrm{P}<0.001$; Table 2$)$ and also correlated with the Weiss score with a cutoff $=4(\mathrm{P}=0.04)$.

We conclude that for these patient series p53 expression was related to the clinical behavior of ACT in children and adults and these findings support a role for p53 in ACT progression. 
The distinction between benign and malignant ACT has been approached by a combination of histological, immunohistochemical and macroscopic parameters. Modern imaging studies allow the detection of small adrenal cortical lesions that may be uncorrectly diagnosed. Failure of conventional gross and light microscopy exams to predict the clinical course of ACT has stimulated several groups to look for other methods to improve the determination of the biological potential of this group of neoplasms. Most studies of the morphologic criteria for malignancy in ACT specimens have not discriminated between pediatric and adult tumors (8$10)$. As a result, the literature often advocates using the same morphologic criteria of malignancy for both and there remains a persistent tendency for the majority of pediatric ACT to be classified as malignant. Ribeiro et al. (3), reviewing the medical records of 40 Brazilian children with ACT, observed that tumor weight greater than 100 $\mathrm{g}$ and tumor size greater than $200 \mathrm{ml}$ were associated with an unfavorable outcome.

Whether p53 overexpression and muta-

$\begin{aligned} & \text { Table } 1 . p 53 \text { expression detected by immunohistochemical methods according to the } \\
& \text { follow-up of children with adrenocortical tumor. }\end{aligned}$
\begin{tabular}{lcc} 
p53 & Clinically benign, N (\%) & Clinically malignant, N (\%) \\
\hline $\begin{array}{l}\text { Negative } \\
\text { Positive }\end{array}$ & $4(100)$ & $0(0)$ \\
\end{tabular}

Negative $(0 /+)$; positive $(++)$.

$\mathrm{P}=0.026$ (chi-square test).

Table 2. Analysis of disease-free survival (DFS) in adults with adrenocortical tumor according to p53 expression detected by immunohistochemical methods (KaplanMeier).

\begin{tabular}{lcrcc}
\hline p53 & Categories & N & \%DFS at 24 months & \%DFS at 60 months \\
\hline Negative & 0 & 25 & 80 & 63 \\
& $(+)$ & 6 & 100 & 100 \\
Positive & $(++)$ & 2 & 0 & 0 \\
\hline
\end{tabular}

$\mathrm{P}<0.001$ (log rank test). tions can be used as specific molecular markers in ACT specimens remains uncertain. Mutations of the p53 gene have been recognized in a wide variety of human malignancies, but there are few studies involving ACT.

McNicol et al. (14) did not correlate p53 immunostaining pattern with $\mathrm{PCR} / \mathrm{SSCP}$ evidence of mutation or disease-free survival within adrenal cortical carcinomas. In 1998, Venara et al. (16) studied prognostic markers in 16 functional ACT in children and found that the expression of $\mathrm{p} 53$ protein appeared as a promising marker of poor prognosis. Recently, in July 2001, Ribeiro et al. (17) in a study involving 36 pediatric adrenal cortical carcinomas in southern Brazil, where the incidence is 10-15 times higher than that of pediatric ACT worldwide, found that 35 of 36 patients had an identical germline point mutation of p53 encoding an R337H amino acid substitution. They also reported that in tumor cells the wild-type allele was deleted and mutant p53 protein accumulated within the nuclei. Latronico et al. (18), investigating the presence of this mutation in a series of 55 patients (37 adults and 18 children) with benign and malignant sporadic adrenocortical tumors, observed that the presence of this mutation was related to an unfavorable prognosis in most of the adults, but not in the children with ACT. Barzon et al. (19), in a immunohistochemical analysis of $\mathrm{p} 53$ expression in 79 sporadic $\mathrm{ACT}$, found an association between p53 expression and carcinomas, but not in benign neoplasms and concluded that mutations in the p53 gene are frequent in adrenocortical carcinomas and might be used as a marker for malignancy.

We opted to use a more accessible p53 expression test as an indicator of p53 mutation. $\mathrm{p} 53$ mutations stabilize the $\mathrm{p} 53$ protein and thus the mutated protein has a longer half-life than the wild-type protein. This fact results in accumulation of the mutant protein in the cell nuclei, allowing immunohisto- 
chemical detection.

Although the number of patients in the present series, 57, is not very large, the data suggested that the expression of immunoreactive $\mathrm{p} 53$ is related to the clinical behavior of ACT in children and adults. However, predicting the clinical behavior of the pediatric group is still a problem and effort should be devoted to the objective of looking for more refined molecular and cytogenetic markers.

\section{Acknowledgments}

\author{
The authors thank Cristina A. Martins for \\ technical support.
}

\section{References}

1. Gandour MJ \& Grizzle WE (1986). A small adrenocortical carcinoma with aggressive behavior. An evaluation of criteria for malignancy. Archives of Pathology and Laboratory Medicine, 110: 1076-1079.

2. Tang CK \& Gray GF (1975). Adrenocortical neoplasms. Prognosis and morphology. Urology, 5: 691-695.

3. Ribeiro RC, Neto RS, Schell MJ, Lacerda L, Sambaio GA \& Cat I (1990). Adrenocortical carcinoma in children: A study of 40 cases. Journal of Clinical Oncology, 8: 67-74.

4. Lack EE, Mulvihill JJ, Travis WD \& Kozakewich HPW (1992). Adrenal cortical neoplasms in pediatric and adolescent age group. Clinicopathologic study of 30 cases with emphasis on epidemiological and prognostic factors. Pathology Annual, 27: 1-53.

5. Cagle PT, Hough AJ, Pysher J, Page DL, Johnson EH, Kirkland RT, Holocombe JH \& Hawkins EP (1986). Comparison of adrenal cortical tumors in children and adults. Cancer, 57: 2235-2237.

6. Mendoça BB, Lucon AM, Menezes CAV, Saldanha LB, Latronico AC, Zerbini C, Madureira G, Domenice S, Albergaria AP, Camargo MHA, Halpern A, Liberman B, Arnhold IJP, Bloise W, Andriolo A, Nicolau W, Silva FAQ, Wroclaski E, Arap S \& Wajchemberg BL (1985). Clinical, hormonal and pathological findings in a comparative study of adrenocortical neoplasms in childhood and adulthood. Journal of Urology, 154: 1-6.

7. Wooten MD \& King DK (1993). Adrenal cortical carcinoma. Epidemiology and treatment with mitotane and a review of the literature. Cancer, 72: 3145-3155.

8. Hough AJ, Hollifield JW, Page DL \& Hartmann WH (1979). Prognostic factors in adrenal cortical tumors. American Journal of Clinical Pathology, 72: 390-399

9. Weiss LM (1984). Comparative histologic study of 43 metastasizing and nonmetastasizing adrenocortical tumors. American Journal of Surgical Pathology, 8: 163-169.

10. Van Slooten H, Schaberg A, Smeenk D \& Moolenaar AJ (1985). Morphologic characteristics of benign and malignant adrenocortical tumors. Cancer, 55: 766-773.

11. Mitsudomi T, Oyama T, Kusano T, Osaki T, Nakanishi R \& Shirakusa $T$ (1993). Mutations of the p53 gene as a predictor of poor prognosis in patients with non-small-cell lung cancer. Journal of the National Cancer Institute, 85: 2018-2023.
12. Bosani S, Viale G, Bossi P, Maggioni M, Coggi G, Murray JJ \& Lee AKC (1994). Cytoplasmatic accumulation of p53 protein: an independent prognostic indicator in colorectal adenocarcinoma. Journal of the National Cancer Institute, 86: 681-687.

13. Sredni ST, De Camargo B, Lopes LF, Teixeira R \& Simpson A (2001). Immunohistochemical detection of p53 protein expression as a prognostic indicator in Wims tumor. Medical and Pediatric Oncology, 37: 455-458.

14. McNicol AM, Nolan CE, Struthers AJ, Farquharson MA, Hermans J \& Haak HR (1997). Expression of p53 in adrenocortical tumors: Clinicopathological correlations. Journal of Pathology, 181: 146-152.

15. Chang F, Syrjanen S \& Syrjanen K (1995). Implications of the p53 tumor-suppressor gene in clinical oncology. Journal of Clinical Oncology, 13: 1009-1022.

16. Venara M, Sanchez Marull R, Bergada I, Gamboni M \& Chemes H (1998). Functional adrenal cortical tumors in childhood: a study of ploidy, p53-protein and nucleolar organizer regions (AgNORs) as prognostic markers. Journal of Pediatric Endocrinology and Metabolism, 11: 597-605.

17. Ribeiro RC, Sandrini F, Figueiredo B, Zambetti GP, Michalkiewicz E, Lafferty AR, DeLacerda L, Rabin M, Cadwell C, Sampaio G, Cat I, Stratakis CA \& Sandrini R (2001). An inherited p53 mutation that contributes in a tissue-specific manner to pediatric cortical carcinoma. Proceedings of the National Academy of Sciences, USA, 98: 9330-9335

18. Latronico AC, Pinto EM, Domenice S, Fragoso MC, Martin RM, Zerbini MC, Lucon AM \& Mendonça BB (2001). An inherited mutation outside the highly conserved DNA-binding domain of the p53 tumor suppressor protein in children and adults with sporadic adrenocortical tumors. Journal of Clinical Endocrinology and Metabolism, 86: 4970-4973.

19. Barzon L, Chilisi M, Fallo F, Martignoni G, Montagna L, Palu G \& Boscaro M (2001). Molecular analysis of CDKN1C and TP53 in sporadic adrenal tumors. European Journal of Endocrinology, 145: 207-212.

20. Weiss LM, Medeiros LJ \& Vickery Jr AL (1989). Pathologic features of prognostic significance in adrenocortical carcinoma. American Journal of Surgical Pathology, 13: 202-206. 